\title{
Contraception
}

Contraception 62 (2000) 113-116

Original research article

\section{Oral contraception and cardiovascular risk factors during adolescence}

\author{
Dominique Paulus*, Annie Saint-Remy, Michel Jeanjean \\ Interuniversity Association for Cardiovascular Disease Prevention, Clos Chapelle-Aux-Champs, 30/53, 1200 Brussels, Belgium
}

Received 2 June 2000; accepted 25 July 2000

\begin{abstract}
The objective of the present study was to analyze the pattern of oral contraceptive (OC) use in teenagers and to examine the relationship between OC use and other cardiovascular risk factors. The study was conducted in 24 Belgian secondary schools. Most students (1526 adolescents aged 12-17 years) agreed to participate (participation rate: 83.6\%). Smoking, physical activity habits, menarche, and OC use were assessed by a self-administered questionnaire. Total cholesterol level, blood pressure and anthropometric measurements were also measured. Fourteen per cent of mature girls $(14 \%, \mathrm{n}=92)$ were OC users. Two-thirds of them $(66.3 \%, \mathrm{n}=61)$ were taking OC which contained either gestodene or desogestrel. Blood pressure and BMI were similar for OC users and non-users. Total cholesterol level was significantly higher in OC users than in non-users $(191 \mathrm{mg} / \mathrm{dL}$ versus $172 \mathrm{mg} / \mathrm{dL})$. Logistic regression model confirmed the significant influence of OC use on total cholesterol level ( $O R=3.08)$. OC users were also often smokers ( $39 \%$ versus $20 \%$ for non-users). In conclusion, the present study has found significant relationships between OC use and cardiovascular risk factors i.e., high total cholesterol and smoking. The first implication is a need for further research on lipoprotein profile in young OC users. Secondly, the combined use of OC and smoking in teenagers calls for preventive actions. () 2000 Elsevier Science Inc. All rights reserved.
\end{abstract}

Keywords: Oral contraceptives; Cardiovascular risk factors; Adolescence

\section{Introduction}

Epidemiological data on oral contraceptive (OC) use during adolescence are scarce, although respectively, two studies have estimated a prevalence equal to 17 and $28 \%$ in 16 -year-olds [1,2]. However, this medication might have effects on the users' cardiovascular risk factors. Many studies have analyzed and reviewed them in adult women [3-7]. In particular, the effects of third-generation pills on the risk of thromboembolism or myocardial infarction have been carefully studied [8-12]. Little is known on the health effects of OC use during adolescence. In particular, OC users from this age group have often a different lifestyle from the other girls. The combination between these factors and OC use might have an influence on their health. The objective of the current study was therefore to analyze the association between $\mathrm{OC}$ use and other cardiovascular risk factors in a population of Belgian adolescents.$$
27 .
$$

* Corresponding author. Tel.: +32-2-764-53-44; fax: +32-2-764-53-

E-mail address: Dominique.Paulus@cumg.ucl.ac.be (D. Paulus).

\section{Materials and methods}

\subsection{Survey population}

The present survey was carried out in the southern part of Belgium i.e., the province of Luxembourg. Eligibility criteria were age (12-17 years), Belgian nationality, and residence in the province. The participants were recruited by a multiclustered sampling technique. First, twenty-four secondary schools were randomly selected out of the 48 schools in the province. Secondly, a type of education was selected in each school. Belgian adolescents have the choice between higher learning education (i.e., theoretical courses) and technical education (including practical courses). Either the higher learning education or the technical learning education was randomly chosen in each school, with probability proportional to the students' distribution in the province. Finally, classes were taken at random as cluster units within the education type selected for the school. The eligible population in the selected classes had 1,826 subjects. Most of them $(83.6 \%, \mathrm{n}=1,526)$ participated in the study i.e., 742 boys and 784 girls. The characteristics of the participants are displayed in Table 1. Of the 300 nonrespondents, 108 were not at school during the survey and 
Table 1

Characteristics of the participants

\begin{tabular}{|c|c|c|c|c|}
\hline \multirow[b]{2}{*}{ Age } & \multicolumn{2}{|c|}{ Boys } & \multicolumn{2}{|c|}{ Girls } \\
\hline & $\mathrm{N}$ & $\%$ & $\mathrm{~N}$ & $\%$ \\
\hline 12 years & 86 & 12 & 96 & 13 \\
\hline 13 years & 155 & 21 & 145 & 18.5 \\
\hline 14 years & 138 & 18.5 & 119 & 15 \\
\hline 15 years & 130 & 17 & 147 & 18.5 \\
\hline 16 years & 139 & 18.5 & 139 & 17.5 \\
\hline 17 years & 94 & 13 & 138 & 17.5 \\
\hline All & 742 & 100 & 784 & 100 \\
\hline
\end{tabular}

192 subjects refused to participate. The first reasons put forward were recent medical examination $(\mathrm{n}=31)$, omission of the appointment $(\mathrm{n}=24)$ and parental refusal $(\mathrm{n}=$ 19). Ethical approval was secured beforehand and written consents were obtained from all participants.

\subsection{Data collection}

Information on pubertal status and OC use was collected through a confidential self-administered questionnaire (i.e., formula and duration of use). Other questions on lifestyle included smoking and physical activity habits. Blood pressure, anthropometric indices measurement, and total cholesterol level were also measured. Blood pressure measurement was carried out according to the Task Force on Blood pressure in children [13]. The anthropometric measurements (i.e., height, weight, triceps, and subscapular skinfolds) followed the guidelines of the World Health Organization [14]. Total cholesterol levels were analyzed according to the recommendations of the expert panel on high blood cholesterol in children [15]. The measurement was performed using the Reflotron ${ }^{\circledR}$ method [16]. Quality control procedures included double measurements by external observers, checks at data entry and during data processing.

\subsection{Statistical analyses}

Statistical analyses were performed using a SAS ${ }^{\circledR}$ statistical package [17]. Statistical $t$-tests were used for comparing 2 means and analysis of variance was applied for more than two subgroups. $\chi^{2}$ tests were used for categorical variables and logistic regression analysis for the relation between OC use and other cardiovascular risk factors.

\section{Results}

Six-hundred-fifty-two girls $(83.7 \%, \mathrm{n}=652)$ had had their menarche. The median age of menarche was 12.7 years. Fourteen per cent of mature girls $(14 \%, \mathrm{n}=92)$ were OC users and the mean duration of use was 11 months $(95 \%$ CI: 1-36 months). The prevalence of OC use increased from
Table 2

OC use by age group

\begin{tabular}{lll}
\hline Age & No. OC users & $\begin{array}{l}\% \text { OC users in } \\
\text { the age group }\end{array}$ \\
\hline 12 years $(\mathrm{n}=96)$ & 0 & - \\
13 years $(\mathrm{n}=145)$ & 0 & - \\
14 years $(\mathrm{n}=119)$ & 3 & $2 \%$ \\
15 years $(\mathrm{n}=147)$ & 17 & $11 \%$ \\
16 years $(\mathrm{n}=139)$ & 25 & $18 \%$ \\
17 years $(\mathrm{n}=138)$ & 47 & $34 \%$ \\
All girls $(\mathrm{n}=\mathbf{7 8 4})$ & $\mathbf{9 2}$ & \\
\hline
\end{tabular}

2 to $34 \%$ between 14 and 17 years of age (respectively, 2\%, $11 \%, 18 \%$, and $34 \%$ in $14,15,16$, and 17 year olds) (Table 2). Table 3 summarizes the formulas of the OC used by the participants. Most of them used low-dose pills with gestodene or desogestrel (mono- or triphasic formulas). Monophasic formulas containing either cyproterone or norgestimate were also reported. Levonorgestrel was less frequently used.

Table 4 compares the risk factors between OC users and non-users from the same age group (i.e., the 15-17 year olds). Systolic blood pressure level was similar in both groups (i.e., $122 \mathrm{mmHg}$ ) and diastolic blood pressure did not differ significantly between OC users and non-users (i.e., 72 and $74 \mathrm{mmHg}$, respectively, $\mathrm{p}$ for the difference $>$ 0.10). Body mass index was also similar in OC users and non-users (21.6 and 21.5, respectively). The major finding was the significant difference in total cholesterol level between users and non-users. OC users had a mean total cholesterol equal to $191 \mathrm{mg} / \mathrm{dL}(\mathrm{SD}=34 \mathrm{mg} / \mathrm{dL}$ ) whereas the non-users exhibited a mean equal to $172 \mathrm{mg} / \mathrm{dL}$ only $(\mathrm{SD}=30 \mathrm{mg} / \mathrm{dL})$. The influence of OC use on total cholesterol was further analyzed by a weighted logistic regression model with total cholesterol as dependent variable. The results confirmed that $\mathrm{OC}$ use was significantly $(\mathrm{OR}=3.08$, $\mathrm{p}<0.01)$ associated with high cholesterol level whereas the other factors (e.g., age, BMI, physical activity) were nonsignificant.

Sixty-one OC users $(\mathrm{n}=61)$ were taking formulas containing either desogestrel or gestoden. Their total choles-

Table 3

OC users: detailed formulas (unknown: $\mathrm{n}=4$ )

\begin{tabular}{rllll}
\hline No. & Type & EE & Progestin & $(\mathrm{mg})$ \\
\hline 26 & Monophasic & $0.030 \mathrm{mg}$ & Gestodene & $(0.075)$ \\
19 & Triphasic & $0.03 / 0.04 / 0.03$ & Gestodene & $(0.05 / 0.07 / 0.1)$ \\
14 & Monophasic & $0.020 \mathrm{mg}$ & Desogestrel & $(0.15)$ \\
12 & Monophasic & $0.035 \mathrm{mg}$ & Cyproterone & $(2)$ \\
8 & Monophasic & $0.035 \mathrm{mg}$ & Norgestimate & $(0.025)$ \\
3 & Triphasic & $0.03 / 0.04 / 0.03$ & Levonorgestrel & $(0.05 / 0.075 / 0.125$ \\
2 & Monophasic & $0.030 \mathrm{mg}$ & Desogestrel & $(0.15)$ \\
2 & Monophasic & $0.030 \mathrm{mg}$ & Levonorgestrel & $(0.15)$ \\
1 & Monophasic & $0.035 \mathrm{mg}$ & Norethisterone & $(1.0)$ \\
1 & Biphasic & $0.05 \mathrm{mg}$ & Levonorgestrel & $(0.05-0.125)$ \\
\hline
\end{tabular}


Table 4

Comparison of risk factors between OC users and non-users aged 15-17 years

\begin{tabular}{llll}
\hline & OC user $(\mathrm{n}=89)$ & Non-users $(\mathrm{n}=329)$ & $\begin{array}{l}\mathrm{p} \text {-value for the } \\
\text { difference }\end{array}$ \\
\hline BMI (S.D.) & 21.6 & 21.5 & $>0.10$ \\
Systolic BP (S.D.) & $122 \mathrm{mmHg}(10.5)$ & $122 \mathrm{mmHG}$ & $>0.10$ \\
Diastolic BP (S.D.) & $72 \mathrm{mmHg}(9.8)$ & $74 \mathrm{mmHg}(9.8)$ & $>0.10$ \\
Total cholesterol (S.D.) & $191 \mathrm{mg} \mathrm{dL}^{-1}(34)$ & $172 \mathrm{mg} \mathrm{dL}^{-1}(30)$ & $<0.001$ \\
Smoking prevalence & $40 \%(\mathrm{n}=35)$ & $25 \%(\mathrm{n}=82)$ & $<0.001$ \\
\hline
\end{tabular}

terol and blood pressure levels were compared to the values of the other OC users. Total cholesterol levels were similar in both groups $(191 \mathrm{mg} / \mathrm{dL})$ and blood pressure levels were slightly lower in third generation OC users (i.e., $122 \mathrm{~mm} \mathrm{Hg}$ versus $125 \mathrm{~mm} \mathrm{Hg}$ for SBP and $73 \mathrm{~mm} \mathrm{Hg}$ versus $76 \mathrm{~mm}$ $\mathrm{Hg}$ for DBP). These differences did not reach the level of statistical significance but the small group sizes did not allow for drawing definitive conclusions.

Finally, smoking and physical activity habits were compared between OC users and non-users. Both groups reported similar leisure-time physical activity i.e., a mean of 5.5 hours per week. Forty percent $(40 \%, \mathrm{n}=35)$ of OC users were smokers versus $25 \%(\mathrm{n}=82)$ of non-users ( $\mathrm{p}$ for the difference $<0.01$ ). The combined use of OC and smoking was associated with the education of the participants. Thirty percent $(30 \%, \mathrm{n}=52)$ of the girls in the technical option were $\mathrm{OC}$ users and nearly half of them were also smokers $(46 \%, \mathrm{n}=23)$. On the opposite, $16 \%(\mathrm{n}=40)$ of the adolescent girls in the higher learning option were OC users and $30 \%$ of them were also smokers.

\section{Discussion}

The first objective of the present study was to analyze the prevalence of OC use in this adolescent population. The participants represented $8 \%$ of the adolescents of the province and the participation rate was high (83.6\%). A quarter (26\%) of the teenagers aged 16-17 years was OC user. This proportion is similar to the proportion obtained in a sample of 16-year-old Finnish girls but lower than the prevalence recorded in a study from The Netherlands $[1,2]$. The last Belgian Health Interview survey has found that $\mathrm{OC}$ was the first contraceptive method used in 15-17 year olds i.e., $85 \%$ of the interviewees using a contraceptive method were taking OC [18]. The prevalence of OC use in 15-17 year olds was equal to $28.1 \%$ in this national survey. The present study had a prevalence equal to $21 \%$ in the same age group, which might be explained by the setting of the study i.e., secondary schools in a rural area. By comparison, $69 \%$ of the women from the same province use a family planning method and in particular, $42 \%$ are OC users [18].

The second objective of the study was to analyze the relation between $\mathrm{OC}$ use and cardiovascular risk factors in teenagers. Consequences of $\mathrm{OC}$ use have been widely in- vestigated in adult women but less studied in adolescents. Recommendations for the prescription of $\mathrm{OC}$ to adolescents are, therefore, derived from the recommendations written for adult women [19-21]. The common effects of OC use include hypercoagulation, increase in blood pressure, lipoprotein and carbohydrates changes, weight gain, and headaches. These side effects have decreased with new formulas, containing less estrogen and new progestin components. However, in the current study, OC use influenced substantially the adolescents' total cholesterol level. The difference between users and non-users was large $(19 \mathrm{mg} /$ dL), even after a short duration of use ( $90 \%$ of the users had been taking their OC for less than 2 years). The influence of OC use on total cholesterol level has been demonstrated in other studies conducted among adolescents [22,23]. However, caution is needed in the interpretation of this high total cholesterol level as the lipoprotein profile change depends on the OC formula. Third-generation formulas containing either gestodene or desogestrel have been found to induce beneficial effects on lipoprotein profile e.g., a slight rise in HDL-cholesterol [24-27]. Research in young populations is, therefore, needed to confirm these positive effects in adolescents. The new OC formulas are also supposed to have little influence on blood pressure level $[3,26,28]$. The present study supports this hypothesis as no significant difference in blood pressure was found between OC users and non-users. Finally, the absence of effect on weight confirms the results of another study conducted in adolescents [29].

As a final point, an important finding was the high smoking prevalence in young OC users. Forty percent of them were smokers in comparison with a quarter of the non-users group. This association was also reported in other adolescent and adult populations [22,30-32]. The present study showed that the combined use of OC and cigarettes existed in one out of 10 girls aged 15 to 17 . This association was more frequent in adolescents with a technical education. This finding has important consequences for planning preventive actions.

\section{Conclusion}

OC use in teenagers deserves special attention given its high prevalence coupled with potential health consequences 
(including the associated lifestyle habits). In particular, this study has shown that the level of total cholesterol was significantly higher in OC users than in non-users. Further studies should analyze the impact on the lipoprotein profile. Moreover, OC users are frequently also smokers, despite the well-known risks of this association. All physicians should be aware of this association when they prescribe OC to adolescents. On a public health level, preventive actions should target the combined use of OC and cigarettes in teenagers in order to avoid later consequences on cardiovascular disease incidence.

\section{References}

[1] Kosunen E, Rimpela A, Rimpela M. Sixteen-year-old oral contraceptive users in Finland, 1981-1993. Scand J Soc Med 1995:23:236-41.

[2] Van Hoff M, Hirasing R, Kaptein M, Koppenaal C, Voorhorst F, Schoemaker J. The use of oral contraceptives by adolescents for contraception, menstrual cycle problems or acne. Acta Obstet Gynecol Scand 1998;77:898-904.

[3] Archer D, Maheux R, DelConte A, et al. Efficacy and safety of a low-dose monophasic combination oral contraceptive containing 100 $\mu \mathrm{g}$ levonorgestrel and $20 \mu \mathrm{g}$ ethinyl estradiol. Am J Obstet Gynecol 1999;181:S39-44.

[4] Beral V, Hermon C, Kay C, Hannaford P, Darby S, Reeves G. Mortality associated with oral contraceptive use: 25-year follow-up of cohort of 46,000 women from Royal College of General Practitioners' oral contraception study. BMJ 1999;318:96-100.

[5] Dunn N, Thorogood M, Faragher B, et al. Oral contraceptives and myocardial infarction: results of the MICA case-control study. BMJ 1999;318:1579-84.

[6] Farley T, Collins J, Schlesselman J. Hormonal contraception and risk of cardiovascular disease. Contraception 1998;57:211-30.

[7] Lachnit-Fixson U. The role of triphasic levonorgestrel in oral contraception: a review of metabolic and hemostatic effects. Gynecol Endocrinol 1996;10:207-18.

[8] Farmer R, Lawrenson R, Thompson C, Kennedy J, Hambleton I. Population-based study of risk of venous thromboembolism associated with various oral contraceptives. Lancet 1997;349:83-8.

[9] Jick H, Jick S, Gurewich V, Myers M, Vasilakis C. Risk of idiopathic cardiovascular death and nonfatal venous thromboembolism in women using oral contraceptives with differing progestagen components. Lancet 1995;346:1589-93.

[10] Poulter N, Chang C, Farley T, Marmot M, Meirik O. Effect on stroke of different progestagens in low oestrogen dose oral contraceptives. Lancet 1999;354:301-2.

[11] Spitzer W, Lewis M, Heinemann L, Thorogood M, MacRae K. Third generation oral contraceptives and risk of venous thromboembolic disorders: an international case-control study. BMJ 1996;312:83-8.

[12] World Health Organization Collaborative Study of Cardiovascular Disease, and Steroid Hormone Contraception. Effect of different progestagens in low oestrogen oral contraceptives on venous thromboembolic disease. Lancet 1995;346:1582-88.
[13] Task Force on Blood Pressure in Children. Report of the Second Task Force on Blood Pressure Control in Children. Pediatrics 1987;79:124.

[14] National Food, and Nutrition Institute Warsaw-Nutrition Unit, WHO Regional Office for Europe, Copenhagen. Measuring obesity-classification and description of anthropometric data. Report on a WHO consultation on the epidemiology of obesity. 1988.

[15] NCEP Expert Panel on Blood Cholesterol Levels in Children and Adolescents. National Cholesterol Education Program: Report of the Expert Panel on Blood Cholesterol Levels in Children and Adolescents. Pediatrics 1992;89(Suppl):525-76.

[16] Lapinleimu H, Viikari J, Jokinen E, et al. Cholesterol measurements by Reflotron dry chemistry in infants, children and adults. Scand J Clin Lab Invest 1994;54:61-5.

[17] SAS Institute Publications. SAS ${ }^{\circledR}$ software: abridged reference, version 6, 1st Edn. Cary, NC: SAS Institute Inc, 1994.

[18] Demarest S, Tafforeau J, Leurquin P, Van Der Heyden J, Van Oyen H. La santé de la population en Belgique-Enquête de santé par interview, 1997: Centre de Recherche Opérationnelle en Santé Publique, Institut Scientifique de la Santé Publique-Louis Pasteur, Brussels, Belgium; 1998. Report No.: D/1998/2505/07.

[19] American Academy of Pediatrics. Contraception and adolescents. Pediatrics 1999;104:1161-6.

[20] Cerel-Suhl S, Yeager B. Update on oral contraceptive pills. Am Fam Physician 1999;60:2073-84.

[21] Gold M. Prescribing and managing oral contraceptive pills and emergency contraception for adolescents. Pediatr Clin North Am 1999;46: 695-718.

[22] Flint P, Lapane K, Barbour M, Derby C, Carleton R, Hume A. Cardiovascular risk profiles of oral contraceptive users and non-users: a population-based study. Prev Med 1995;24:586-90.

[23] Teichmann A. Metabolic profile of six oral contraceptives containing norgestimate, gestodene and desogestrel. Int J Fertil 1995;40:S94-104.

[24] Akerlund M, Almstrom E, Hogstedt S, Nabrink M. Oral contraceptive tablets containing 20 and 30 micrograms of ethinyl estradiol with 150 micrograms desogestrel. Acta Obstet Gynecol Scand 1994;73:136-43.

[25] Laurendeau L. Desogestrel contraceptives: the perfect pill for lipids? Can Fam Physician 1996;42:62-71.

[26] Fotherby K. Twelve years of clinical experience with an oral contraceptive containing 30 micrograms ethinyl estradiol and 150 micrograms desogestrel. Contraception 1995;51:3-12.

[27] Lobo R, Skinner J, Lippman J, Cirillo S. Plasma lipids and desogestrel and ethinyl estradiol: a meta-analysis. Fertil Steril 1996;65: $1100-9$.

[28] Fuchs N, Dusterberg B, Weber-Diehl F, Muhe B. The effect on blood pressure of a monophasic oral contraceptive containing ethinylestradiol and gestodene. Contraception 1995;51:335-9.

[29] Risser W, Gefter L, Barratt M, Risser J. Weight change in adolescents who used hormonal contraception. J Adol Health 1999;24:433-6.

[30] Raitakari O, Porkka K, Rasanen L, Viikari J. Relations of lifestyle with lipids, blood pressure and insulin in adolescents and young adults. The Cardiovascular Risk in Young Finns Study. Atherosclerosis 1994;111:237-46.

[31] Sharpe C. Smoking among oral contraceptive users in Quebec in 1987. J Clin Epidemiol 1994:47:313-23.

[32] Kosunen E, Rimpela A, Kaprio J, Berg M. Oral contraception and smoking. Eur J Public Health 1997;7:29-33. 